\title{
EFFECT OF MELTING PARAMETERS DURING SYNTHESIS ON THE STRUCTURE AND PROPERTIES OF TIN FLUORIDE PHOSPHATE GLASSES
}

\author{
Nora Iturraran ${ }^{1}$, Karine Huraux $^{1}$, Yuqing Bao ${ }^{2}$, David Thomas Gawne ${ }^{2 *}$ and Jean Guilment ${ }^{1}$ \\ ${ }^{1}$ Arkema Cerdato, Route de Launay, Serquigny 27470, France \\ ${ }^{2}$ London South Bank University, Borough Road, London, SE1 0AA United \\ Kingdom \\ *Corresponding Author
}

\begin{abstract}
FTIR and Raman spectroscopy indicate the glass structure during synthesis of tin fluoride phosphate glass was pyrophosphate, mainly built up from $\mathrm{Q}^{1}$ end groups with a low concentration of $\mathrm{Q}^{2}$ polymeric chains. However, sub-optimal melting produced significantly higher concentrations of orthophosphate $\mathrm{Q}^{0}$ structural units. The variations in $\mathrm{NH}$ and $\mathrm{P}-\mathrm{OH}$ vibrations in the spectra revealed that a critical time and temperature of melting were necessary for the conversion of $\mathrm{NH}_{4} \mathrm{H}_{2} \mathrm{PO}_{2}$ to produce sufficient $\mathrm{P}_{2} \mathrm{O}_{5}$ for glass forming. During melting, $\mathrm{P}_{2} \mathrm{O}_{5}$ and $\mathrm{SnF}_{2}$ form a low-temperature melt, which facilitates melting of the $\mathrm{SnO}$ and promotes the formation of a more stable glass structure. The fluorine breaks the P-O-P bonds and induces depolymerisation. The density of the glass reached a maximum at $450^{\circ} \mathrm{C}$ for 25 minutes driven by the need for conversion of $\mathrm{NH}_{4} \mathrm{H}_{2} \mathrm{PO}_{4}$ to $\mathrm{P}_{2} \mathrm{O}_{5}$ and miscibility of $\mathrm{SnO}$ in the melt. Inadequate melting times and temperatures gave low $\mathrm{T}_{\mathrm{g}}$ values because of weak F-Sn and F-P linkages. Glass stability improved with melting due to increased $\mathrm{P}_{2} \mathrm{O}_{5}$ and $\mathrm{SnO}$ miscibility enabling stronger Sn-O-P linkages. The results show that melting conditions during synthesis strongly influence critical glass properties and future industrial scale-up will require an understanding of optimum processing.
\end{abstract}

Key words: phosphate glass; melting conditions; glass transition temperature; degradation; chemical durability. 


\section{INTRODUCTION}

Phosphate glasses have been developed over recent years with much lower glass transition temperatures $\left(\mathrm{T}_{\mathrm{g}}\right)$ than those of conventional silicate glasses [1,2]. Specifically, phosphate glasses can have $\mathrm{T}_{\mathrm{g}}$ values as low as $100^{\circ} \mathrm{C}$ as compared with $550^{\circ} \mathrm{C}$ for typical silicate-based glasses. These unique thermal properties offer major potential in engineering applications including sealing [3], nuclear waste storage [4] and biomedical implants [5].

A further possible application is in polymer composites. Phosphate glasses have melting temperatures in a broadly similar range to organic polymers and so co-processing by extrusion in which both components are fluid is a possibility. A molten rather than a solid (as it is the case in conventional polymer processing) glass phase should in principle allow much higher glass loadings and enhanced properties. This paper is directed at developing an understanding of the mechanisms of melting and defining the processing conditions of phosphate glasses for co-extrusion with polymers with the ultimate aim of producing highperformance glass-polymer hybrids.

The structure of vitreous phosphates is based on a molecular tetrahedral building block [6,7]. Phosphorus is a pentavalent ion and so the formation of a phosphorus-oxygen tetrahedron with four bridging oxygens would result in an impracticable unit with a net positive charge of +1 . Nevertheless, a charge-neutral tetrahedron can be formed if one of the oxygens forms a double bond with the pentavalent phosphorus ion $(\mathrm{P}=\mathrm{O})$, while the other three oxygens form bridging oxygens $(\mathrm{P}-\mathrm{O}-\mathrm{P})$ with adjacent tetrahedra. In practice, the tetrahedra link up, using the covalent bridging oxygens, to form various phosphate anions. The tetrahedra may be classified using the $\mathrm{Q}^{\mathrm{i}}$ terminology [6,7], where $\mathrm{i}$ represents the number of bridging oxygens per tetrahedron. Phosphate glasses can be made with a range of structures, from a cross-linked network of $\mathrm{Q}^{3}$ tetrahedra as in vitreous $\mathrm{P}_{2} \mathrm{O}_{5}$, to polymer-like meta-phosphate chains of $\mathrm{Q}^{2}$ tetrahdra, to glasses based on small pyrophosphate $\left(\mathrm{Q}^{1}\right)$ and orthophosphate $\left(\mathrm{Q}^{0}\right)$ anions, depending on the oxygen-to-phosphorus ratio as set by the glass composition.

Low-temperature glasses tend to show inferior chemical durability in humid environments and this hygroscopic characteristic limits their practical application. However, glasses have now been developed with much higher stability, particularly tin phosphate oxyfluorides 
$[8,9)]$. The addition of $\mathrm{SnO}$ to binary stannous fluorophosphates glass resulted in a decrease in the volatility of the melt and dramatic improvements in the chemical durability of the glass $[8,9]$. The substitution of $\mathrm{SnO}$ for $\mathrm{SnF}_{2}$ drastically reduced dissolution to rates comparable to soda-lime-silica glass [7,9]. The increase in chemical durability is attributed to the weaker linkages of Sn-F-Sn, Sn-F-P and P-F-P being replaced by the stronger Sn-O-Sn, Sn-O-P and P-O-P linkages.

The composition of the glass will have a direct bearing on its blending with polymers as well as influencing the properties of the resulting composite [10]. A tin fluoride phosphate glass with a molar composition of $50 \mathrm{~mol} \%$ tin fluoride $\left(\mathrm{SnF}_{2}\right), 20 \mathrm{~mol} \%$ tin oxide $(\mathrm{SnO})$ and 30 mol\% phosphorus pentoxide $\left(\mathrm{P}_{2} \mathrm{O}_{5}\right)$ was selected for investigation due to its unique combination of low $\mathrm{T}_{\mathrm{g}}$, rheological properties, water resistance and chemical durability [8]. The low $\mathrm{T}_{\mathrm{g}}$ has the possibility of making the phosphate glass fluid during polymer processing. In addition, the glass has been reported to have an affinity with some polymers, which may provide possibilities for hybridization [11-13].

For a fixed glass composition, however, the processing conditions are also expected to influence the formation of its final structure and the properties. No systematic investigations were found in the literature on the quantitative effect of melting conditions on the final properties of tin fluoride phosphate glass. This paper will characterize the effect of melting on glass structure [13-16] and properties [17-19] by techniques including FTIR, Raman, DSC, TGA and density and complex viscosity in comparison with related systems in the literature. The research will have value in understanding the sensitivity of glass performance to melting conditions and relevance for upscaling of the glass synthesis in the development of possible future industrial applications.

\section{EXPERIMENTAL DETAILS}

\subsection{Glass formation}

A tin fluoride phosphate glass with a molar composition of $50 \% \mathrm{Sn} \mathrm{F}_{2}+20 \% \mathrm{Sn} \mathrm{O}+30 \%$ $\mathrm{P}_{2} \mathrm{O}_{5}$ was prepared from reagent-grade powders of tin fluoride $\left(\mathrm{SnF}_{2}\right)$, tin oxide $(\mathrm{SnO})$ and ammonium dihydrogen phosphate $\left(\mathrm{NH}_{4} \mathrm{H}_{2} \mathrm{PO}_{4}\right.$ powders supplied by Sigma Aldrich Ltd. The ammonium dihydrogen phosphate is a source for producing $\mathrm{P}_{2} \mathrm{O}_{5}$. The ingredients were premixed and ground at room temperature. Melting of mixed ingredients was performed in a 
porcelain crucible placed in a convection oven for various times at various pre-setting temperatures in order to study the influence of melting conditions on glass properties and their thermal stability. The detailed melting conditions used in the investigation are given in Table 1. Finally, the molten glass was poured into a stainless steel plate mould and cooled down to room temperature for structure and property evaluation.

Table 1: Glass melting conditions

\begin{tabular}{ccc}
\hline Samples & $\begin{array}{c}\text { Temperature } \\
\left({ }^{\circ} \mathrm{C}\right)\end{array}$ & Time (minntes) \\
\hline 1 & 350 & 25 \\
2 & 400 & 25 \\
$3(\mathrm{a}, \mathrm{b}, \mathrm{c}, \mathrm{d}, \mathrm{e}, \mathrm{f}, \mathrm{g})$ & 450 & $15,20,25,30,35,40,45$ \\
4 & 500 & 25 \\
5 & 550 & 25 \\
\hline
\end{tabular}

\subsection{Properties}

The density of glass is known to vary greatly with its composition. This paper, however, investigates the effect of melting conditions on the end properties of the glass. The density of the glasses under study was measured using a Sartorius IAC 210P digital balance according to the standards ISO 1183-1:2004 and ASTM D792:2008. The samples were weighed in air and in an immersion liquid and calculated automatically by the integrated software. The results are presented and discussed in Sections 3 and 4 respectively.

The thermal behaviour of the glasses made under various melting conditions were analysed. The glass transition temperature (Tg) was determined by differential scanning calorimetry (Netzsch F1ASC). The sample was heated from $20^{\circ} \mathrm{C}$ to $300^{\circ} \mathrm{C}$ in dry nitrogen atmosphere at a linear heating rate of $2^{\circ} \mathrm{C} / \mathrm{min}$. The tests were run twice for each sample in order to remove the effect of thermal history. The mass loss of glasses was determined using thermogravimetric analyzer (TG209 F1 Netzsch). The test was carried out within the temperature range of $25^{\circ} \mathrm{C}$ to $550^{\circ} \mathrm{C}$ at a heating rate of $10^{\circ} \mathrm{C} / \mathrm{min}$ under atmosphere. The tests were run twice for each samples and the average mass loss was reported.

The rheological properties of the glass were measured by a rotational rheometer (Physica MCR 301) at temperatures of 230,250 and $270^{\circ} \mathrm{C}$ respectively. These temperatures were selected to simulate the extrusion processing temperatures that would be applied for meltblending the glasses with polymers [10]. The tests were run using parallel plate geometry at a frequency of $1 \mathrm{~Hz}$. 


\subsection{Glass Structure}

The structural variations of the glasses induced by melting conditions and moisture were investigated using both FTIR and Raman spectroscopy The infrared spectra of the glass powder samples were measured using a Vertex 70 (FTIR) spectrometer in the range 400$4000 \mathrm{~cm}^{-1}$ in absorbance mode to estimate the glass structural changes. A Bruckner Raman Spectrometer was also used to observe the variation in vibrational, rotational and other low frequency modes in the glass samples. The chemical durability was determined by assessing the moisture attack on the samples using the Raman spectrometer.

\section{RESULTS}

\subsection{Glass formation}

The final performance of the glass was found to be influenced by the conditions pertaining in glass formation and melting. Specifically, the glass properties were sensitive to the temperature of melting over the range of 200 to $550^{\circ} \mathrm{C}$ and time over 15 to 45 minutes. This study investigates the response of properties and structure to glass melting parameters.

\subsection{Properties}

The density of the glass was measured (Figure 1) and found to rise with melting time to reach a maximum and a plateau at 25 minutes for a fixed melting temperature of $450^{\circ} \mathrm{C}$. Raising the melting temperature also increased the density and reached a maximum at $450^{\circ} \mathrm{C}$ (Figure 2 ) for a fixed time of 25 minutes.

The experimental results in Figure 3 show that the glass transition temperature $T_{g}$ of the glass is strongly influenced by the duration of melting at a temperature of $450^{\circ} \mathrm{C}$. The $\mathrm{Tg}$ changes from a value of approximately $100^{\circ} \mathrm{C}$ at melting time of 15 minutes to $160^{\circ} \mathrm{C}$ at 45 minutes. A similar pattern of behaviour is found with melting temperature: the $\mathrm{Tg}$ changes from $93^{\circ} \mathrm{C}$ at $400^{\circ} \mathrm{C}$ to $154^{\circ} \mathrm{C}$ at $500^{\circ} \mathrm{C}$ (Figure 4 ).

Thermogravimetric analysis (TGA) was carried out to measure the mass loss of glasses made under different melting conditions during synthesis. Figure 5(a) shows that the total mass loss at $550^{\circ} \mathrm{C}$ and the rate of mass loss both diminish with increasing melting time during synthesis. In addition, Figure 5(b) shows the rate of mass loss falls with rising melting temperature up to $500^{\circ} \mathrm{C}$. The results are internally consistent in that the samples with the greatest mass losses had the lowest onset temperatures. Table 2 gives the percentage of cumulative mass loss at two temperature ranges due to volatiles and glass degradation. The results confirm that thermal stability of the glass is improved with the extent of melting during synthesis. 


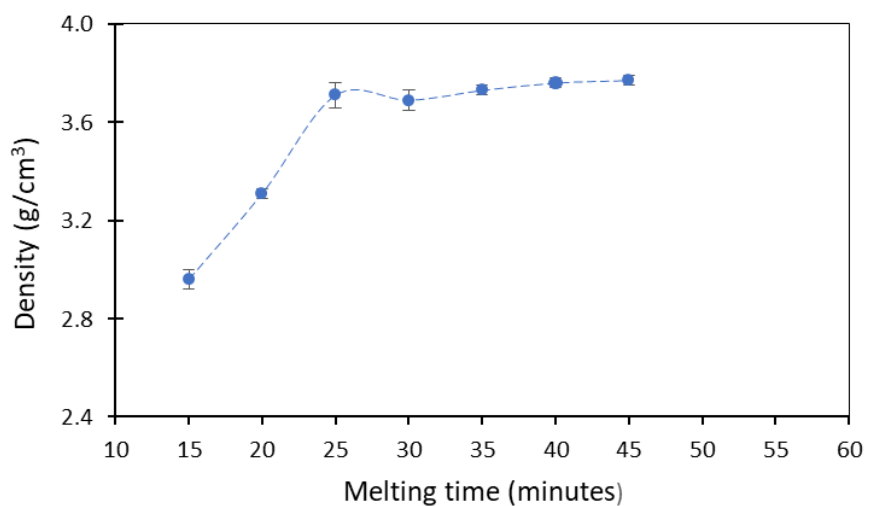

Fig. 1. Measured densities of tin fluoride phosphate glass melted at $450^{\circ} \mathrm{C}$ for different times.

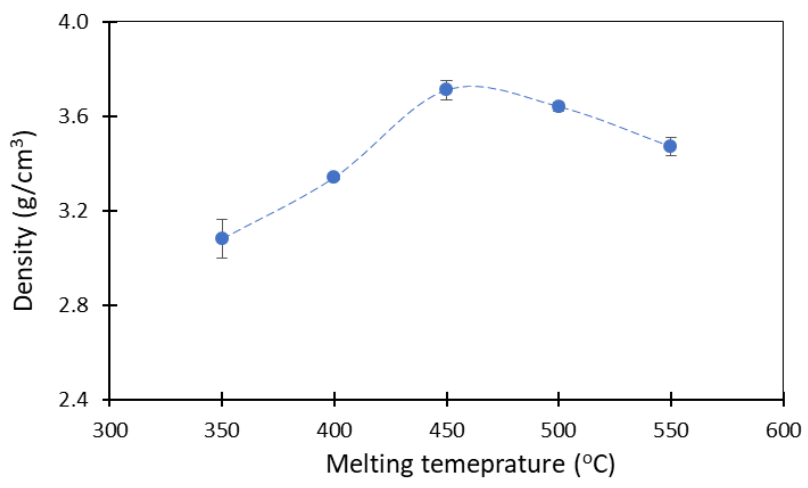

Fig 2. Measured densities of tin fluoride phosphate glass melted at different temperatures for 25 minutes.

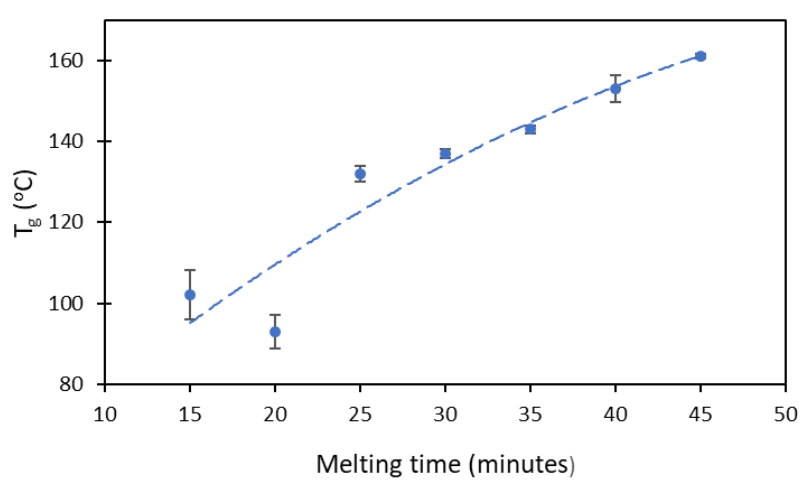

Fig. 3. The effect of melting time on the glass transition temperature $\left(\mathrm{T}_{\mathrm{g}}\right)$ as measured by DSC of tin fluoride phosphate glass melted at $450^{\circ} \mathrm{C}$.

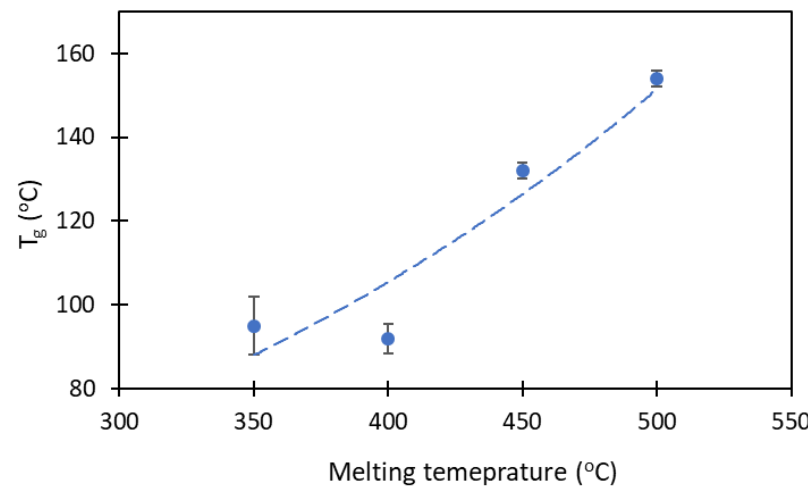

Fig. 4. The effect of temperature of melting on the glass transition temperature $\left(\mathrm{T}_{\mathrm{g}}\right)$ of tin fluoride phosphate glass produced at a fixed melting time of 25 minutes.

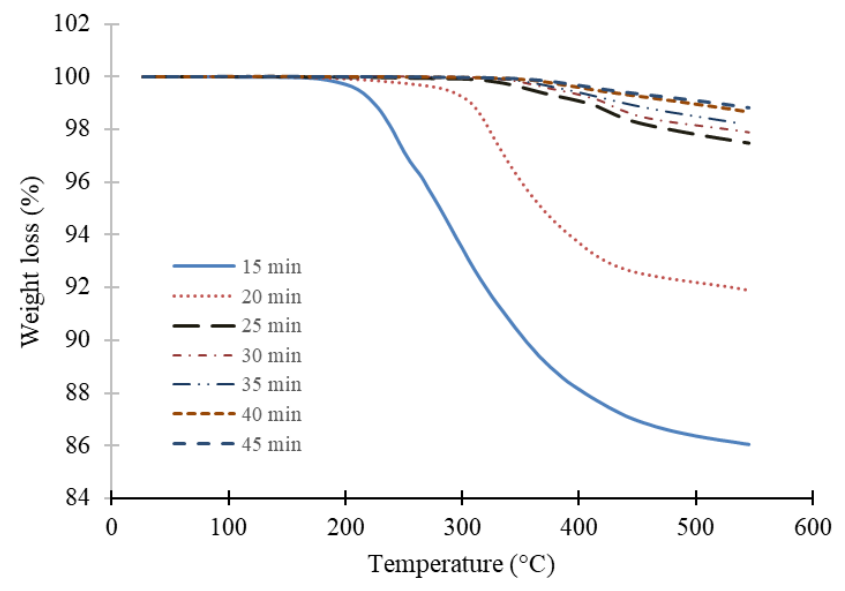

Fig 5a. Thermogravimetric analysis (TGA) results showing the effect of melting time during synthesis (at fixed temperature of $450^{\circ} \mathrm{C}$ ) on the mass loss of tin fluoride phosphate glass

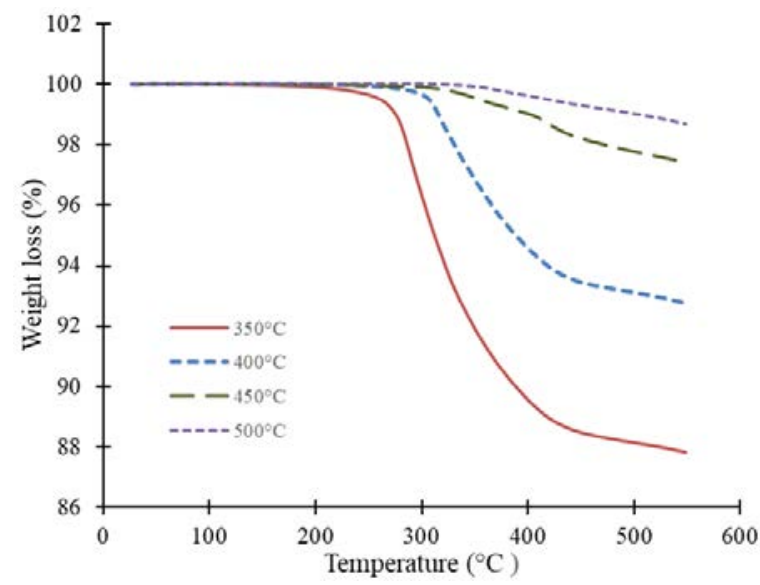

Fig 5 b. Thermogravimetric analysis (TGA) results showing the effect of melting temperature during synthesis (at fixed time of 25 minutes) on the mass loss of tin fluoride phosphate glass

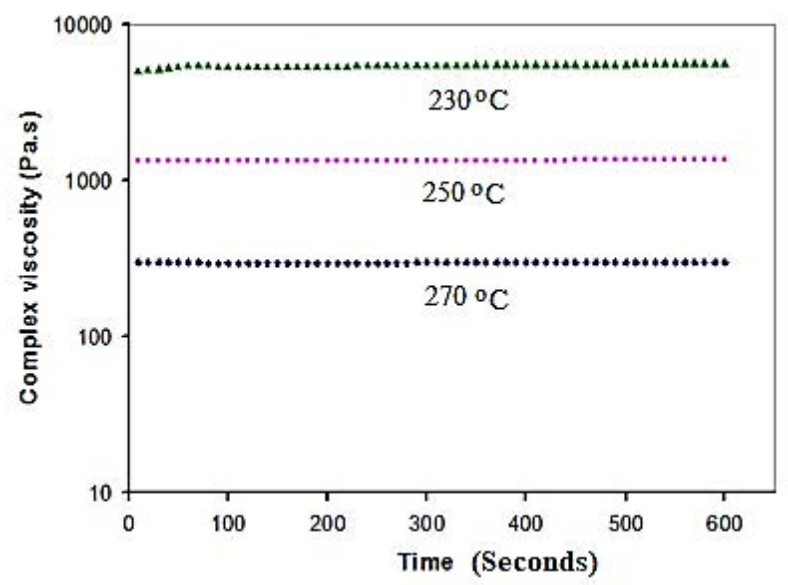

Fig. 6. Measured time dependent complex viscosity of tin fluoride phosphate glass for various temperatures. 
Table 2: Effect of the melting time and melting temperature during synthesis on the mass changes (using TGA) of tin fluoride phosphate glass

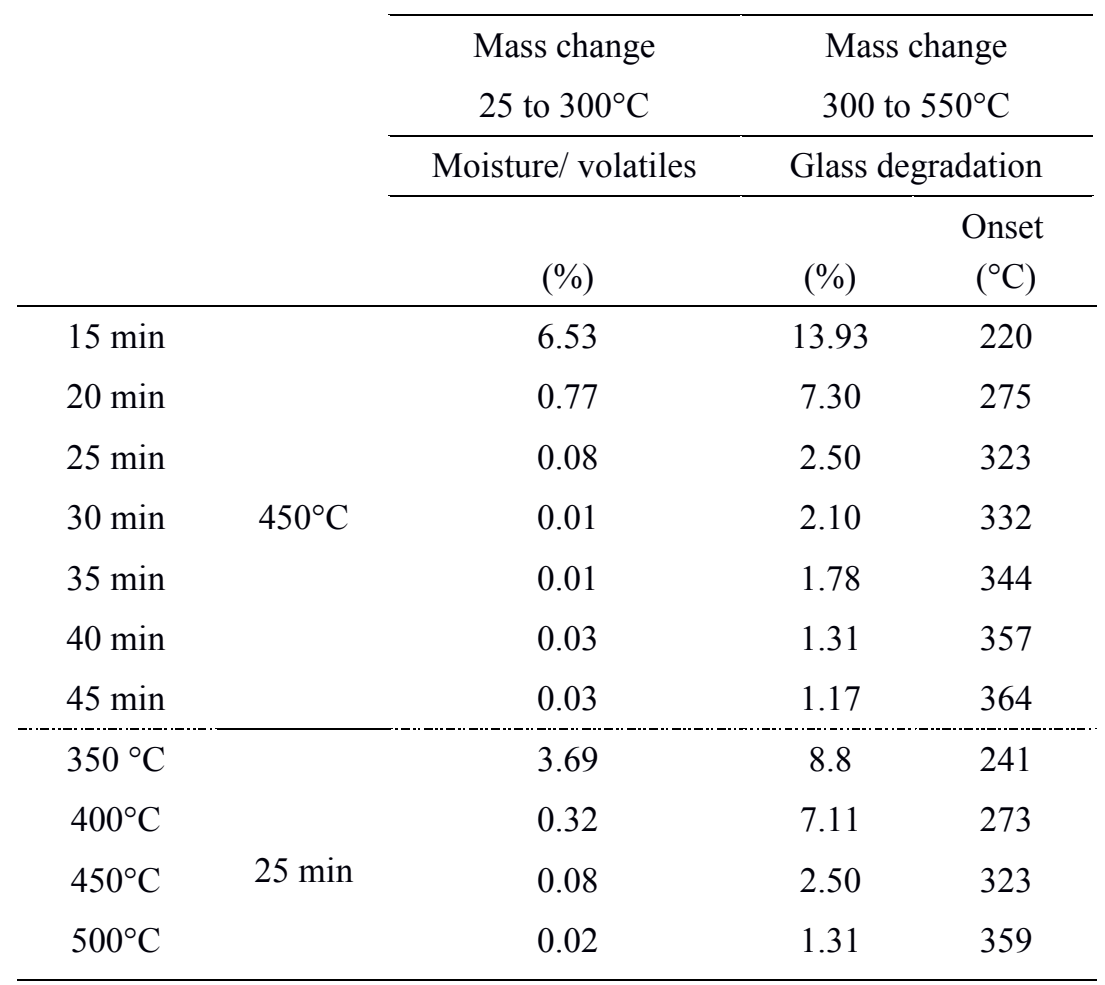

The effect of the synthesis conditions on the stability of the structure of the final glass solid was investigated. Two different glasses were made: one melted for 20 minutes at $450^{\circ} \mathrm{C}$ and the other for 35 minutes at the same temperature of $450^{\circ} \mathrm{C}$. The glass transition temperature was determined by DSC immediately after melt-synthesis and then after re-heating for 5 minutes at $250^{\circ} \mathrm{C}$, which was similar to the thermal conditions in polymer extrusion. The as-melted 20minute glass had a $\mathrm{Tg}$ of $92^{\circ} \mathrm{C}$ and this was reduced to $75^{\circ} \mathrm{C}$ after re-heating. However, the $\mathrm{Tg}$ of the as-melted 35 minute-glass was not affected by reheating. These results indicate that melting for 35 minutes at $450^{\circ} \mathrm{C}$ during synthesis produced a relatively stable glass structure, whereas melting for 20 minutes did not. The results in the previous paragraph on thermal degradation and those in this paragraph on the stability of glass solid are both related to the strength of the glass network. This is considered further in Section 4.4.

The rheological properties of the glasses are important for their potential applications and were measured using a rotational rheometer. The glass melted at $450^{\circ} \mathrm{C}$ for 25 minutes during synthesis was investigated (as it displayed optimum properties) at temperatures of $230^{\circ} \mathrm{C}$, $250^{\circ} \mathrm{C}$ and $270^{\circ} \mathrm{C}$ in order to simulate polymer extrusion. Figures 6 give the results in terms of time-independent complex viscosity $\eta^{*}$ and show a linear viscoelastic relationship indicating that the glass behaves as a Newtonian fluid under the temperatures tested. The complex viscosity of the glass reduces linearly and significantly with increased temperatures. 


\subsection{Glass Structure}

The glass structure during the melting process was examined using Fourier Transform InfraRed Spectroscopy (FTIR) and Raman Spectroscopy. Figures 7 and 8 show the infrared absorption spectra and Figure 9 the Raman spectra from the tin fluoride phosphate glasses produced under different melting times and temperatures.

It was observed that white spots formed on the surfaces of glasses melted at low temperatures (below $450^{\circ} \mathrm{C}$ ) and short times (below 20 minutes) after exposure to the atmosphere for seven days. These results on the stability of the glass are investigated further particularly by Raman Spectroscopy as given in Figure 10 and discussed in Section 4.4.

\section{DISCUSSION}

\subsection{Overview.}

The experimental results in the previous section indicate there is a correlation between melting conditions during synthesis and the properties of the solidified glass product. The following discussion will investigate this correlation with the aim of showing whether or not there is a link between the melting conditions and the structure of the glass. The existence of such a causal link will improve the understanding and control of the process.

\subsection{Glass formation and density}

The development of the glass structure during the melting process was studied using Fourier Transform Infrared Spectroscopy (FTIR) and Raman Spectroscopy. Figures 7 and 8 show the infrared absorption spectra from the tin fluoride phosphate glasses produced under different melting times and temperatures. The infrared absorption bands in the range $3400-2700 \mathrm{~cm}^{-1}$ are related to the stretching vibration of $\mathrm{NH}$ and the peak centred at $1430 \mathrm{~cm}^{-1}$ to the bending vibration of $\mathrm{NH}$ [13-18]. Both of these vibrations are typical of substances containing $\mathrm{NH}_{4}$. The intensity of the peak and the band decrease with increasing the melting time and temperature. The $\mathrm{NH}_{4}$ vibrations completely disappear at a melting temperature of $450^{\circ} \mathrm{C}$ for a melting time of 40 minutes and above as shown in Figure 7. Figure 8 shows a similar pattern of behaviour but with respect to temperature. The peaks relating to the stretching vibrations (3400 - 2700 $\left.\mathrm{cm}^{-1}\right)$ and bending vibrations $\left(1430 \mathrm{~cm}^{-1}\right)$ of $\mathrm{NH}$ gradually reduce with increasing melting temperature and eventually disappear at $500^{\circ} \mathrm{C}$ (Figure 8). 


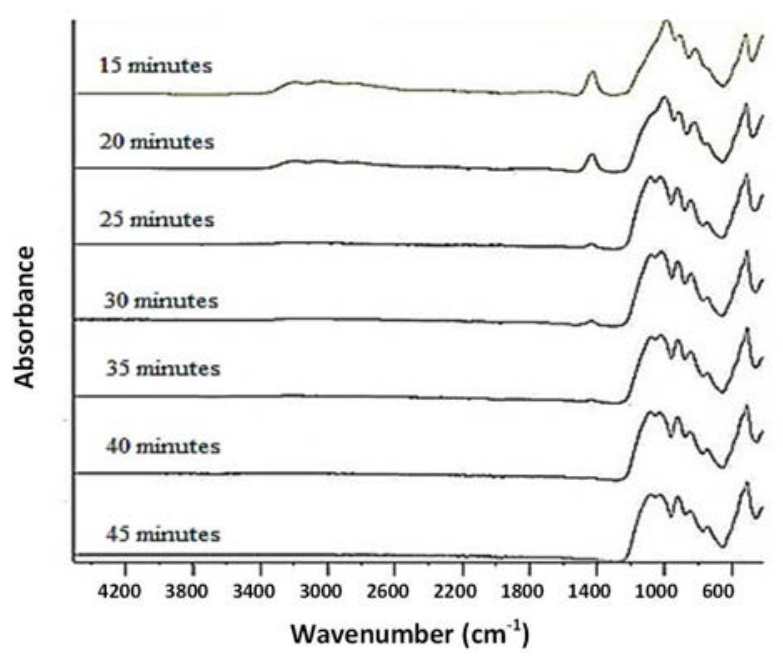

Fig. 7. Infrared spectra of tin fluoride phosphate glass produced at various melting times at a fixed melting temperature of $450^{\circ} \mathrm{C}$

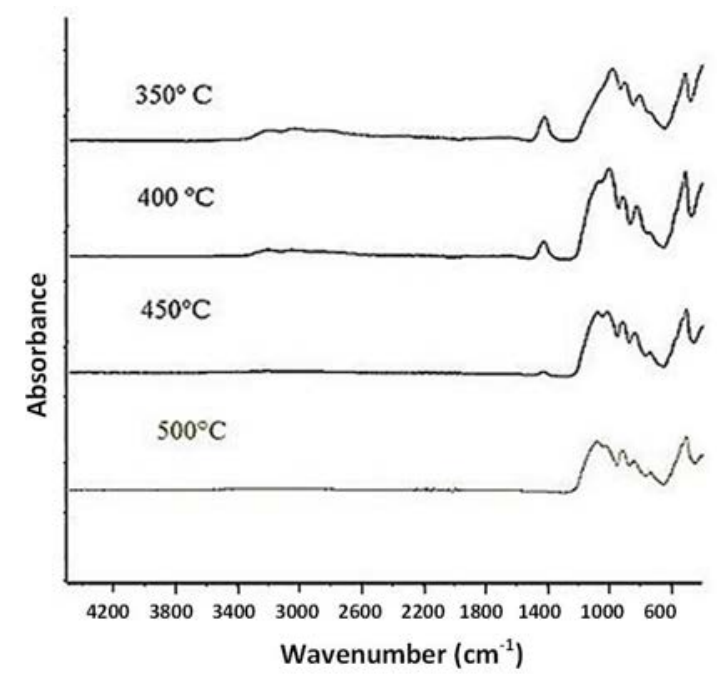

Fig. 8. Infrared spectra of tin fluoride phosphate glass produced at various melting temperatures for a fixed melting time of 25 minutes

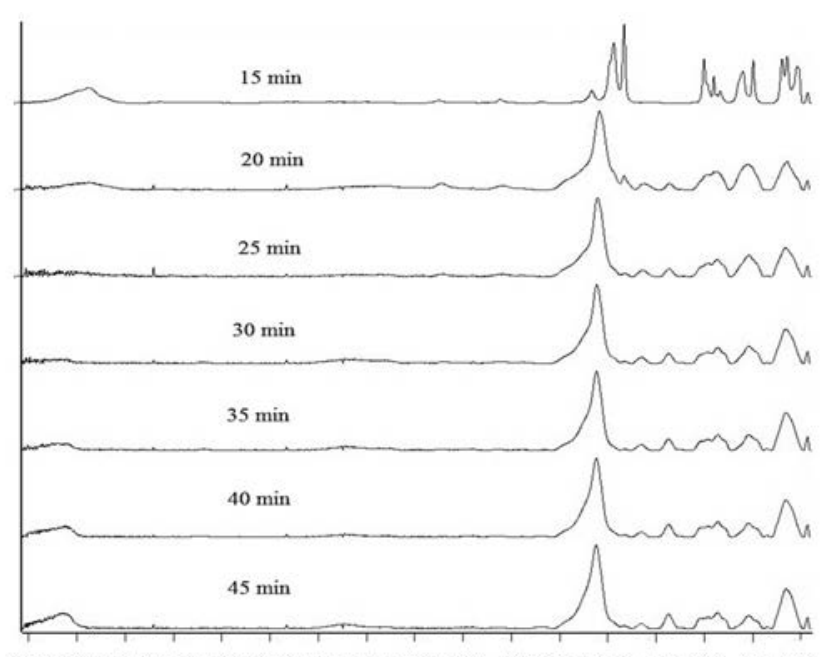

$3400320030002800260024002200200018001600 \quad 140012001000800600400200$

Wavenumber $\left(\mathrm{cm}^{-1}\right)$

Figure 9. Raman spectra of tin fluoride phosphate glass produced at various melting times at a fixed melting temperature of $450^{\circ} \mathrm{C}$

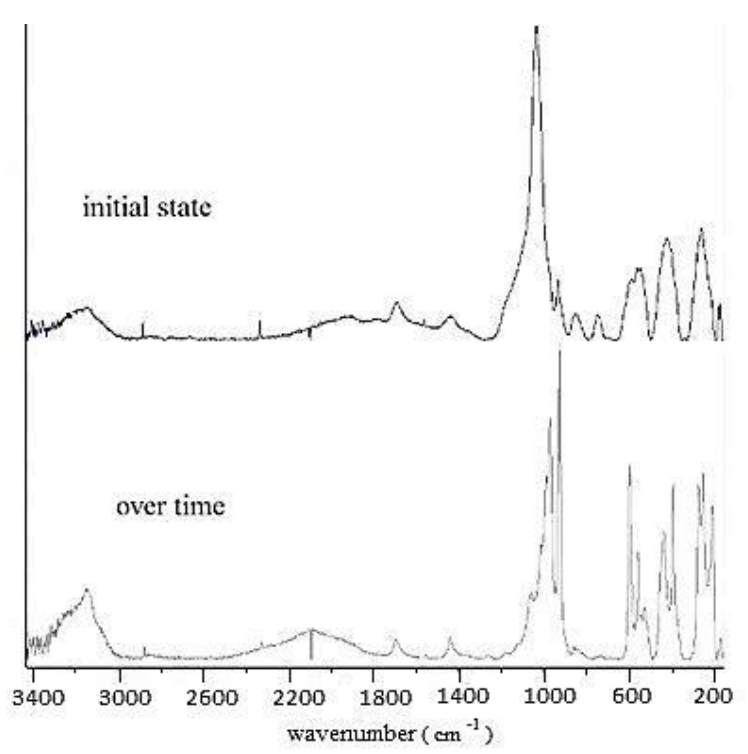

Figure 10. Raman spectra in the initial as-melted state of glass

$\left(20\right.$ minutes at $450^{\circ} \mathrm{C}$ ) and aged over time for 7 days 
Alongside this change in FTIR peaks related to the NH bond, samples with the least time and lowest temperature of melting $\left(15\right.$ minutes at $450^{\circ} \mathrm{C}$ and 25 minutes at $350^{\circ} \mathrm{C}$ ) show a peak centred at $990 \mathrm{~cm}^{-1}$, which is likely to be related to the $\mathrm{P}-\mathrm{OH}$ bond vibration $[14,18,19]$. In addition, a P-OH vibration was clearly detected at 15 minutes melting by Raman spectroscopy with a peak at $924 \mathrm{~cm}^{-1}$ as shown in Figure 9. This confirms that the Raman spectroscopic results are in agreement with those of FTIR. A further Raman peak is evident at $970 \mathrm{~cm}^{-1}$, which is characteristic of $\left(\mathrm{PO}_{4}{ }^{3-}\right)$ symmetric stretching and is related to short phosphate chains indicative of the $\mathrm{Q}^{0}$ structural unit [15-18]. This suggests that these two samples include an orthophosphate structure, which generally occurs in phosphate glass compositions with less than $30 \% \mathrm{~mol}_{2} \mathrm{O}_{5}$. Increasing the melting time from 15 to 25 minutes (at $450^{\circ} \mathrm{C}$ ), results in the $990 \mathrm{~cm}^{-1}$ peak shifting to one centred at $1040 \mathrm{~cm}^{-1}$ (Figures 7 and 8), which is related to a $\left(\mathrm{PO}_{4}{ }^{2-}\right)$ stretching vibration of the $\mathrm{Q}^{1}$ structural model. A similar FTIR peak shift also occurs for increasing the melting temperature from 350 to $450^{\circ} \mathrm{C}$ (for 25 minutes). The FTIR spectra of the glass given in Figures 7 and 8 show a vibrational peak shift between the vibration of $\mathrm{Q}^{0}$ $\left(970 \mathrm{~cm}^{-1}\right)$ and the vibration of $\mathrm{Q}^{1}\left(1040 \mathrm{~cm}^{-1}\right)$ with respect to melting conditions, suggesting a transition from $\mathrm{Q}^{0}$ to $\mathrm{Q}^{1}$ is taking place. Raman spectroscopy provides a higher resolution for vibrational identification $[14,18,20]$. The Raman spectroscopic results in Figure 9 indicate that the intensity of the Raman absorbance peak at $924 \mathrm{~cm}^{-1}$ reduces with melting time and disappears at 25 minutes, which suggests the effective elimination of $\mathrm{P}-\mathrm{OH}$ vibrations. The Raman absorbance peak at $970 \mathrm{~cm}^{-1}$ is only present at 15 minutes and the peak shifts to between $1020 \mathrm{~cm}^{-1}$ (for the glass melted for 25 minutes) and $1050 \mathrm{~cm}^{-1}$ (for the glass melted for 45 minutes). These two peaks reside in the wavenumber band of $1020-1050 \mathrm{~cm}^{-1}$, which is attributed to $\mathrm{Q}^{1}$ units (pyrophosphate) with three non-bridging oxygens [21-23].

The P-OH and NH vibrations detected by FTIR and Raman spectroscopy in Figures $7-9$ and described above are attributed to the precursor, $\mathrm{NH}_{4} \mathrm{H}_{2} \mathrm{PO}_{4}$ [19], that is used in the meltsynthesis as a source of $\mathrm{P}_{2} \mathrm{O}_{5}$. The presence of $\mathrm{NH}_{4} \mathrm{H}_{2} \mathrm{PO}_{4}$ in the glasses implies that complete conversion of $\mathrm{NH}_{4} \mathrm{H}_{2} \mathrm{PO}_{4}$ to $\mathrm{P}_{2} \mathrm{O}_{5}$ has not occurred so that the extent of the reaction (as described by Equation 1 below) to form $\mathrm{P}_{2} \mathrm{O}_{5}$ is less than $100 \%$. This results in an orthophosphate structure, which generally occurs in phosphate glasses with less than $30 \%$ mol $\mathrm{P}_{2} \mathrm{O}_{5}$

$$
2 \mathrm{NH}_{4} \mathrm{H}_{2} \mathrm{PO}_{4}=\mathrm{P}_{2} \mathrm{O}_{5}+2 \mathrm{NH}_{3}+3 \mathrm{H}_{2} \mathrm{O}
$$


In general, the spectroscopy in Figures 7 to 9 show that the extent of this decomposition reaction of the precursor depends upon the melting time and temperature during synthesis. This mechanism of precursor decomposition has a major effect on the underlying dependency of properties on melting conditions. A further factor from the spectroscopic results concerns the role of SnO. Lengthening the melting time from 15 minutes to 20 minutes reveals the emergence of a shoulder at $1100 \mathrm{~cm}^{-1}$.This then develops into a peak at 25 minutes after which it becomes constant. This is attributed to the development of Sn-O-P linkages [21, 24] in the glass. Moreover, the Raman spectra (Figure 9) also shows the appearance of $\mathrm{aO}_{3}{ }^{2-}$ vibration with a peak at $1040 \mathrm{~cm}^{-1}$ (equivalent to $\mathrm{Q}^{1}$ ) as the melting time increases from 15 to 20 minutes.

These spectroscopic effects are attributed to the mechanism of melting for the $\mathrm{SnF}_{2}, \mathrm{SnO}$ and $\mathrm{NH}_{4} \mathrm{H}_{2} \mathrm{PO}_{4}$ mixture. During the heating process, the low-temperature materials of $\mathrm{SnF}_{2}$ (melting point $213^{\circ} \mathrm{C}$ ) and $\mathrm{NH}_{4} \mathrm{H}_{2} \mathrm{PO}_{4}$ (melting point $190^{\circ} \mathrm{C}$ ) become active first followed by the much higher-temperature $\mathrm{SnO}$ (melting point $1080^{\circ} \mathrm{C}$ ). The $\mathrm{NH}_{4} \mathrm{H}_{2} \mathrm{PO}_{4}$ melts and decomposes to form $\mathrm{P}_{2} \mathrm{O}_{5}$ (melting point $340^{\circ} \mathrm{C}$ ) as described in Equation 1. This, together with $\mathrm{SnF}_{2}$, form a low-temperature melt, which then facilitates the melting of the $\mathrm{SnO}$. At this stage, the melt will contain the phosphate structural units that will be the basis of the subsequent glass network. Raising the temperature and time of the melting process will increase the kinetics of miscibility of $\mathrm{SnO}$ in the melt and the development of Sn-O-P linkages, which will promote the strengthening of the glass structure $[9,18,19,24]$. Moreover, Figures 8 and 9 show an absence of $\mathrm{NH}$ peaks and $\mathrm{Q}^{0}$ sites and indicate that the reaction described by Equation 1 is now 100\% complete.

This mechanism of melting is also relevant to development of density of the glass. This is seen in Figure 1 to rise with melting time to reach a maximum and plateau at 25 minutes as well as increasing with melting temperature to a maximum at $450^{\circ} \mathrm{C}$ (Figure 2). This pronounced influence of time and temperature of melting on density can therefore be directly related to the incomplete conversion of the $\mathrm{NH}_{4} \mathrm{H}_{2} \mathrm{PO}_{2}$ precursor to $\mathrm{P}_{2} \mathrm{O}_{5}$. The relative lack of $\mathrm{P}_{2} \mathrm{O}_{5}$ at low melting temperatures and times restricts the miscibility of $\mathrm{SnO}$ to the detriment of density.

\subsection{Glass Transition Temperature}


A further property of practical importance is the glass transition temperature $T_{g}$. The $T_{g}$ value of the phosphate glasses under investigation was found to be much lower than conventional soda-lime glasses: $130^{\circ} \mathrm{C}$ compared with $570^{\circ} \mathrm{C}$ respectively. This critical characteristic of these materials underlies the basis of much of their potential.

The glass transition temperature was found experimentally to increase substantially with both the time and temperature of melting (Figures 3 and 4). The corresponding structural investigations showed that low melting temperatures and short times produced a material containing incompletely converted $\mathrm{NH}_{4} \mathrm{H}_{2} \mathrm{PO}_{4}$. The resulting low $\mathrm{P}_{2} \mathrm{O}_{5}$ and phosphorusoxygen tetrahedra content will restrict the phosphate glass-forming ability of the melt. This, in addition to the reduced $\mathrm{SnO}$ miscibility, will result in the formation of predominantly weak linkages (such as F-Sn-F, Sn-P-F and F-P-F) and less of the stronger Sn-O-P linkages [9, 17] resulting in glasses with lower glass transition temperatures.

\subsection{Stability of the glasses}

The mass loss of the tin fluoride phosphate glasses was measured by TGA as described in Section 3. It is pointed out that mass loss can also be considered as being related to undermelting as well as thermal stability. The results in Figures 5a and 5b show the influence of the melting time and temperature on the mass loss of the glass. Table 2 gives the percentages of mass loss and the onset temperature of glass degradation, which shows that thermal stability is initially improved with increasing melting time and temperature. This is attributed to the increased conversion of $\mathrm{NH}_{4} \mathrm{H}_{2} \mathrm{PO}_{4}$ to $\mathrm{P}_{2} \mathrm{O}_{5}$ as well as the enhanced strengthening of the network structure by the increased miscibility of $\mathrm{SnO}$ in the glass. However, Figure 2 shows that above $450^{\circ} \mathrm{C}$, the density falls and Table 2 shows that above $500^{\circ} \mathrm{C}$, the onset temperature of degradation also decreases. These results indicate, therefore, that glass quality initially improves with rising melting temperature due to network strengthening but then declines at approximately $500^{\circ} \mathrm{C}$ owing to thermal degradation.

The infrared absorption spectra in Figures 7 and 8 show a peak at $830 \mathrm{~cm}^{-1}$, which is attributed to the stretching mode of P-F bonds $[15,16]$ and indicates that the P-F bond exists in the glass structure. This substantial content of fluoride favours network depolymerisation: $\mathrm{F}$ breaks the P-O-P bonds to form monofluorophosphate $\left(\mathrm{PO}_{3} \mathrm{~F}\right) \mathrm{Q}^{1}$ units $[17,18,24]$. The high fluoride concentration of the phosphate glasses decreases the average length of the phosphate chains and subsequent conversion leads to pyrophosphate dimers. This process was detected by a Raman peak at $1020 \mathrm{~cm}^{-1}$ due to the symmetric stretching vibration of 
$\left(\mathrm{PO}_{3}{ }^{2-}\right)$ as related to $\mathrm{Q}^{1}$. Both FTIR and Raman spectroscopy results identify the glass structure as pyrophosphate, mainly built up by dimers ( $\mathrm{Q}^{1}$ end groups) with a low content of $\mathrm{Q}^{2}$ polymeric chains. In addition, the Raman spectra in Figure 9 reveals that the presence of the stretching vibration of the P-O-P linkages at $740 \mathrm{~cm}^{-1}$ and not at $693 \mathrm{~cm}^{-1}$, which confirms that the structure is dominated by $\mathrm{Q}^{1}$ sites rather than $\mathrm{Q}^{2}$ sites. These results suggest that the 20-minutes glass was relatively unstable due to a predominance of F-P linkages in the structure.

It was observed that white spots formed on the surfaces of glasses melted at low temperatures (below $450^{\circ} \mathrm{C}$ ) and short times (less than $25 \mathrm{~min}$ ) after exposure of the glass samples to the ambient laboratory environment for seven days. Raman spectroscopy was carried out on the samples and the results (Figure 10) show substantial structural changes have taken place in the short melting time sample (20 minutes) over the seven days. This was not observed in the longer melting time sample (35 min). Figure 10 shows a major peak at $1020 \mathrm{~cm}^{-1}$ in the 'initial state' before ageing, which is indicative of pyrophosphate $\left(\mathrm{Q}^{1}\right.$ unit with three nonbridging oxygens). This is absent after ageing for 7 days (the 'over time' state in Figure 10) but a peak is now evident at $970 \mathrm{~cm}^{-1}$, which is related to the smaller orthophosphate $\mathrm{Q}^{0}$ anions. The observed susceptibility to attack by humidity on ageing is thus attributed to an increased content of $\mathrm{Q}^{0}$ sites, the incomplete conversion of $\mathrm{NH}_{4} \mathrm{H}_{2} \mathrm{PO}_{4}$ to $\mathrm{P}_{2} \mathrm{O}_{5}$ and a preponderance of weak F-P linkages.

\section{Conclusions}

The evolution of the structure of a tin fluoride phosphate glass was assessed using FTIR and Raman spectroscopy and indicated that the glass structure was pyrophosphate, mainly built up by $\mathrm{Q}^{1}$ end groups with a low concentration of $\mathrm{Q}^{2}$ polymeric chains. The variations in $\mathrm{NH}$ and $\mathrm{P}-\mathrm{OH}$ vibrations in the spectra revealed that a critical time and temperature of melting were necessary for the decomposition of $\mathrm{NH}_{4} \mathrm{H}_{2} \mathrm{PO}_{2}$ to produce sufficient $\mathrm{P}_{2} \mathrm{O}_{5}$ for glass forming. It is proposed that the $\mathrm{P}_{2} \mathrm{O}_{5}$ and the $\mathrm{SnF}_{2}$ form a low-temperature melt, which then facilitates the melting of SnO. Increasing the time and temperature of the melting process enhances the kinetics of miscibility of $\mathrm{SnO}$ in the melt and the formation of a more stable glass structure. The spectroscopic results also showed that the substantial fluorine content of the glass acts to break the P-O-P bonds and induce depolymerisation of the network with a major influence on properties. The density of the glass increased with increasing time and temperature of melting to reach a maximum at $450^{\circ} \mathrm{C}$ for 25 minutes. FTIR and Raman spectroscopy showed that this 
was due to the need for complete conversion of $\mathrm{NH}_{4} \mathrm{H}_{2} \mathrm{PO}_{4}$ to $\mathrm{P}_{2} \mathrm{O}_{5}$ as well as full miscibility of $\mathrm{SnO}$ in the melt. The decline of glass quality at temperatures above approximately $500^{\circ} \mathrm{C}$ was due to glass degradation. The glass transition temperature decreased substantially as the extent of melting was reduced. Short melting times and low temperatures gave low transition temperatures due to the low concentrations of $\mathrm{P}_{2} \mathrm{O}_{5}$ and $\mathrm{SnO}$ in the melt, as a result of a preponderance of weak F-P linkages. The degradation temperature and thermal stability improved with the extent of melting due to network strengthening as a result of increased $\mathrm{P}_{2} \mathrm{O}_{5}$ concentration and $\mathrm{SnO}$ miscibility in the melt. The rheological properties were studied over typical polymer processing temperatures $\left(230-270^{\circ} \mathrm{C}\right)$ and showed the glass behaved as a

Newtonian fluid. The glasses with low temperatures and times of melting suffered from thermal and chemical instability due to incomplete conversion of $\mathrm{NH}_{4} \mathrm{H}_{2} \mathrm{PO}_{4}$ to $\mathrm{P}_{2} \mathrm{O}_{5}$ and a preponderance of weak F-P linkages. In general, the melting conditions of tin fluoride phosphate glass need to be controlled sufficiently in order to achieve consistent glass properties and, as a result, optimum processing procedures are required before industrial scale up.

\section{ACKNOWLEDGEMENTS}

The research leading to these results received funding from the European Union Seventh Framework Programme (FP7-MC-ITN) under Grant Agreement No.264710. The authors would like to thank the Directorate-General for Science, Research and Development of the European Commission for financial support of the research.

\section{REFERENCES}

[1] M. Moan, J. Huitric, M. Mederic, J. Jarrin, Rheological properties and reactive compatibilization of immiscible polymer blends, Journal Rheol, 44, 2000, 1227-45

[2] Paul D.R, Bucknall CB, editors. Polymer blends-formulation. Polymer blends, Vol. 1. New York: Wiley; 2000.

[3] W. Donald, P. M. Mallinson, B. L. Metcalfe, A. Gerrard J. A. Fernie, Recent developments in the preparation, characterization and applications of glass- and glass-ceramicto-metal seals and coatings, J Materials Science, 46 (2011) 1975-2000

[4] Man-Sung Yim and K. Linga Murty, Materials issues in nuclear-waste management, Journal of the Minerals, Metals and Materials Society, 52 (9) (2000) 26-29

[5] Ben-Nissan B, Ylanen Ho (2006) Bioactive glasses and glass ceramics, Wiley encyclopedia of biomedical engineering. Wiley, Hoboken 
[6] J.E. Shelby, "Introduction to glass science and technology", Second edition, The Royal Society of Chemistry, 2005, Cambridge, UK.

[7] R.K. Brow, "Review: the structure of simple phosphate glasses", J. Non-Cryst. Solids 263\&264 (2000) 1-28.

[8] P.A.Tick, Water Durable Glasses with Ultra Low Melting Temperature. Physics and Chemistry of Glasses 1984 (25) 149-154.

[9] C.M. Shaw and J.E. Shelby, "Preparation and properties of stannous fluorophosphates glasses", Physics and Chemistry of glasses, 29 (1988) 87-94.

[10] Luciana Serio, David T. Gawne, Yuqing Bao, Eff ect of tin fluoride content on the structure and properties of phosphate glass - polyamide 11 hybrids, European Polymer Journal 99 (2018) 134-141.

[11] S. B. Adalia and J. U.Otaigbe, "Melt Rheology of Tin Phosphate glasses", Journal of Applied Rheology 11, 1 (2001) 10-18.

[12] K.Urman and J.U. Otaigbe, "Rheology of Tin Fluorophosphate glass/Polyamide 12 in the low concentration, regime Rheol. 51, 1172 (2007); doi: 10.1122/1.2789954.

[13] K. Urman, J. U. Otaigbe, New phosphate glass/polymer hybrids - Current status and future prospects, Prog Polym Sci, volume 32, 2007, pages 1462-1498.

[14] Moustafa, Y.M. and K. El-Egili, Infrared spectra of sodium phosphate glasses. Journal of Non-Crystalline Solids, 1998. 240(1-3): p. 144-153.

[15] Y.B. Peng, D.E. Day, Glass Tech, 32 (1991) 200.

[16] L. Montagne, G. Palavit, G. Mairesse, M. Draoui, K. Aomari, M.S. Idrissi, Phys. Chem. Glasses 38 (1) (1997) 15.

[17] X.J. Xu, D.E. Day, Properties and structure of Sn-P-O-F glasses, Phys. Chem. Glasses 31 (1990) 183-8.

[18] K. Sun, W.M. Risen, Solid State Commun. 60 (1986) 697-705.

[19] David R. Lide, (1998). Handbook of Chemistry and Physics (87 ed.). Boca Raton, FL:

CRC Press. pp. 4-40. ISBN 0-8493-0594-2

[20] A.M. Ermov, J. Non-Cryst. Solids 209 (1997) 202-209.

[21] J.F. Ducel, J.J. Videau, K.J. Suh, J. Senegas, J. Alloys Comp. 188 (1992) 157; Phys.

Chem. Glasses 35 (1994) 10.

[22] J. Cha, T. Kubo, H. Takebe, M. Kuwabara, J. Ceram. Soc. Jpn. 116 (8) (2008) 915.

[23] C.N. Banwell, E.M. McCash, Fundamentals of Molecular Spectroscopy, Fourth ed., McGraw-Hill, NewYork, (1994).

[24] D. Möncke, D. Ehrt, Structure and properties of mixed phosphate and fluoride glasses,

Physics and Chemistry of Glasses, 46 (2005) p. 67-71. 
